\title{
Estimating the potential effects of COVID-19 pandemic on food commodity prices and nutrition security in Nepal
}

\author{
Samrat Singh ${ }^{1}$, Sara Nourozi ${ }^{2}$, Laxman Acharya ${ }^{3}$ and Sridhar Thapa ${ }^{4}$ \\ ${ }^{1}$ School of Public Health, St Mary's Campus, Faculty of Medicine, Imperial College London, Norfolk Place, London W2 1PG, UK \\ ${ }^{2}$ Partnership for Child Development, Faculty of Medicine, Imperial College London, Norfolk Place, London W2 1PG, UK \\ ${ }^{3}$ Partnership for Child Development-HGSF Nepal Project, ANSAB, New Baneshwor, Kathmandu, Nepal \\ ${ }^{4}$ UN World Food Programme, Lalitpur, Nepal
}

(Received 6 August 2020 - Final revision received 25 September 2020 - Accepted 7 October 2020)

Journal of Nutritional Science (2020), vol. 9, e51, page 1 of 10

doi:10.1017/jns.2020.43

Abstract

The objective of the paper is to analyse changes in food commodity prices and estimate the potential effects of food price change on nutrition security in Nepal in the context of COVID-19 contagion control measures. It presents a comparative intra-country observational study design looking at events before and during the pandemic (after implementation of contagion control measures). The study design includes three districts, enabling comparison between diverse agro-ecological zones and geographical contexts. The methodology consists of primary data collection, modelling and quantitative analysis. The analysis is based on actual school meal food baskets which represent culturally and nutritionally optimised food baskets, developed by the local community and notional typical household food baskets. End May/early June 2020 is the 'Post-COVID-19' reference point, the same time period in 2019 i.e. June 2019 is the 'Pre-COVID-19' reference point. The study finds a substantial increase in food commodity prices across food groups and districts with marked inter-district variation. For school meal basket, all micronutrients show large average declines ranging from $9 \cdot 5 \%$ for zinc to $11 \%$ for vitamin-A. For household food baskets on average, vitamin-A reduced $37 \%$ followed by iron at $19 \%$, reduction in zinc is low due to the high zinc content in whole grain cereals. COVID-19 control measures are likely to have contributed to substantial price inflation over the reference period with potentially damaging effects on nutrition security in Nepal with serious implications for vulnerable populations.

Key words: Nutrition security: COVID-19: Micronutrients: Nepal

\section{Introduction}

The COVID-19 pandemic has caused a global public health crisis on an unprecedented scale, affecting nearly every country and community on the planet. As the disease continues to spread, we are beginning to get an initial glimpse of the destruction it leaves in its wake. The pandemic and contagion control measures have ravaged economies leading to millions of lost jobs and livelihoods. The need to divert community health and clinical resources and social distancing requirement have led to the disruption of public health and safety net programmes. The most widely used contagion control instrument has been lockdowns and curfews, allowing for only very restricted movement of goods and people.
In Nepal, the national lockdown commenced in the last week of March 2020. It included a ban on transport throughout the country and closure of schools, offices and markets. While all sectors of the economy suffer due to such measures, the impact on agriculture and food availability can be particularly debilitating and profound. Countries such as Nepal, which are resource poor with fragile agricultural economies and underdeveloped supply chains are especially vulnerable. The cumulative impact of lost incomes, disrupted food supply, interrupted safety net programmes and reduced coverage of health interventions can lead to a critical food and nutrition crisis and increase in infant and maternal mortality $^{(1,2)}$.

* Corresponding author: Samrat Singh, email samrat.singh@imperial.ac.uk 
One of the most immediate drivers of food and nutrition insecurity is the increase in food prices. As a coping strategy, poor households replace micronutrient-rich foods such as animal-sourced foods and, fruits and vegetables with cheaper energy-dense foods to preserve caloric intake ${ }^{(3-5)}$. The link between high food prices and food insecurity is wellestablished ${ }^{(4,6,7)}$. Higher food prices are known to increase malnutrition in young children and mothers especially in lowincome and mid-income countries ${ }^{(7-9)}$. The consequences of malnutrition are especially severe for the youngest demography, affecting the development of cognitive abilities which can have significant long term and irreversible impacts on health $^{(10-12)}$. Studies have also shown that children who experience poor nutrition in utero and at a very young age suffer from lifelong negative effects in the form of lost human capital, decreased productivity and lower earnings ${ }^{(13,14)}$.

The pandemic and response measures are causing food and nutrition distress for millions of poor households around the world. As case numbers continue to rise and food production is disrupted, the possible final toll on the health and well-being of an entire generation presents a sobering picture. As is always the case, vulnerable populations in low-income countries are likely to suffer the most. In order to better inform policy and catalyse responses, quantification of the potential impact of the pandemic on food and nutrition security in lowincome countries is required. Such analysis will also help contribute to further research on the medium and long-term impacts of the pandemic on food security and public health.

The present paper investigates the impact of COVID-19 control measures on food prices and models the effect of food price changes on nutrition quality of diets. It specifically examines the effect of price changes on micronutrient intake. The study design includes three districts, enabling comparison between diverse agro-ecological zones and geographical contexts. The paper applies two different approaches to analyse the potential effect of food price increase on the nutritional quality of diets. School meal food basket (SMFB) provides a useful analytical platform to estimate the most realistic effect of price inflation on cost and diet quality based on local, balanced and diversified weekly diets. However, this does not tell us how the diets in the poorest households of the country will be impacted. In order to understand this aspect, the study constructed typical household food baskets (THFBs) for the poorest quintile (quintile-1) for each district and analysed the cost and diet quality implications of food price changes for these baskets.

The structure of the paper is as follows. Section 'Methods' details the approach, methods and materials applied in the study. Methods and materials for each main topic are presented in detail. Section 'Results' describes the results, covering cost and diet quality estimates and analysis. Finally, Section 'Discussion' summarises and analyses the main results, discusses their implications and highlights some limitations of the study.

\section{Methods}

The present paper presents a comparative intra-country observational study analysing events before and during the pandemic (after implementation of contagion control measures).
The design includes primary data collection, modelling and quantitative analysis. The Meal Planning Tool (MPT), a linear programming software developed by Partnership for Child Development (PCD), Imperial College London, was used for nutrient estimations and costings. MPT was coded with relevant food and nutrition data for Nepal.

\section{Nutrient references}

Nutrient data for all commodities is derived from the Nepal Food Composition Table (FCT), 2017, issued by the Department for Food Technology and Quality Control, Government of Nepal. Nepal FCT provided nutrient information for over 567 food items. It does not include zinc values, and occasionally some nutrient values were missing for some commodities and some commodities were missing as such. To address the issue of zinc values and other missing information, data were used from India and Bangladesh FCT's based on the assumption that neighbouring countries would have similar food compositions.

For nutrient requirement estimations, FAO/WHO guidelines and guidelines from India on Estimated Energy Requirement (EER), safe level of intake, acceptable macronutrient distribution range (AMDR), safe level of intake and Recommended Dietary Allowance (RDA), for the specific age group are used, as currently there are no Nepal specific nutrient reference values. Details on reference values for school meals and typical household are provided in the latter part of this section.

\section{Site selection}

We purposively selected three districts of Nepal, representing the main agro-ecological zones and geographical contexts. Bardiya is in Terai (plains), with an open land border with India, Sindhupalchok is in mid-hills with a restricted land border with China and Jumla is in the high mountains. There are also marked differences in the wealth distribution and food security of the study districts based on the different ecological zones, as can be observed from Table 1 .

\section{Food price data and reference period}

The reference period for this analysis is aimed at capturing the potential initial effect of COVID-19 control measures on food prices and diet quality in Nepal. The national lockdown in Nepal due to COVID-19, with a ban on movement of people and goods, commenced on 25 March 2020. In order to allow for some time lag, we chose end May/early June 2020 as the 'Post-COVID-19' reference point. To ensure comparability, we chose the same time period in 2019 i.e. June 2019 as the 'Pre-COVID-19' reference point.

Phone surveys were undertaken to collect food commodity prices for this period from the three study districts. SMFB provided the list of commodities for price data collection. It consists of a wide range of commodities, around 26 food items on average in each district, from across food groups. Condiments, spices and commodities used in small amounts 
Table 1. Wealth distribution and HH food insecurity of study districts (DHS, 2016)

\begin{tabular}{|c|c|c|c|c|c|c|c|}
\hline \multirow[b]{2}{*}{ Ecological zone/District } & \multicolumn{5}{|c|}{ Wealth quintile - \%Age population } & \multicolumn{2}{|c|}{$\begin{array}{l}\mathrm{HH} \text { food insecurity - \%Age } \\
\text { distribution }\end{array}$} \\
\hline & Q-1 & Q-2 & Q-3 & Q-4 & Q-5 & Moderate & Severe \\
\hline Terai/Baridya & $5 \cdot 7$ & $19 \cdot 1$ & 28.9 & $26 \cdot 4$ & 19.9 & 28.9 & $13 \cdot 8$ \\
\hline Hills/Sindhupalchok & $31 \cdot 0$ & 20.5 & $11 \cdot 2$ & $22 \cdot 6$ & $22 \cdot 6$ & $24 \cdot 4$ & $10 \cdot 0$ \\
\hline Mountains/Jumla & $57 \cdot 8$ & 23.4 & $8 \cdot 3$ & $5 \cdot 7$ & 4.9 & $19 \cdot 1$ & $9 \cdot 2$ \\
\hline
\end{tabular}

such as chilly and ginger were not included. Table 2 indicates the number of food commodities by food group for each district for which price data was collected.

Prices were collected from two different independent sources, i.e. traders and farm cooperatives. Price data were verified from a third source, i.e. the World Food Programme (WFP) Nepal's Vulnerability Analysis and Mapping (VAM) unit, by comparing data for some commodities for each district. For the 'Pre-COVID-19' reference point, we chose the same time period in 2019, i.e. May/June 2019. The 'Pre-COVID-19' prices were collected during school meal design workshops and market surveys. Bardiya and Sindhupalchok base prices were collected in August 2018 and Jumla prices were collected in June 2019. For the purposes of the present study, Bardiya and Sindhupalchok prices were inflation adjusted using inflation data from Nepal Central Bank, till June 2019 and validated with actual June 2019 prices for some commodities.

\section{Food price changes}

The food commodity data were coded separately for five food groups. Changes in prices for each district by food group were then analysed. Prices for 2019 and 2020 were averaged for each food group to calculate the change in prices over our reference period.

\section{School meals}

The SMFBs represent culturally, locally and nutritionally optimised food baskets, developed by the local community and currently served as school meals. All school meals were designed at the district level, in participatory workshops based on menu development guidelines. The meals are based on local taste, culture, production and availability for each district. For each district, six separate meals were designed for each day of the school week. The six meals have been combined to comprise an SMFB for this analysis.

Recommended nutritional intakes for school meals were calculated based on FAO/WHO guidelines as endorsed by Nepal
School Meals Nutrition Technical Working Group. Table 3 summarises the nutrient reference values for school meals in Nepal.

We calculated the unit cost of school meals (per child/per meal/per day) for the two points in time based on the food price data. As each set for each district consists of six different meals for six days of the week which are repeated every week, our unit of analysis for nutrient supply is one week. Prices for each actual daily meal vary depending on ingredients. The unit cost is, thus, derived from the average cost of the six meals.

In order to estimate the impact of increased prices on the nutrient intake, we undertook meal adjustment modelling for all school meals for the three districts. The objective of this modelling was to understand and estimate the net effect of price changes on nutrient intake. The basic idea was to adjust all daily meals for the three districts, i.e. eighteen meals, based on 2020 food prices, such that the total cost of each meal remains the same as our baseline reference cost in 2019. This required a reduction in the quantity of each ingredient by a certain amount. We considered different methods for meal adjustment. Each meal was designed by the community with fixed proportions of different ingredients as per local culinary practices, and therefore, we considered it important to maintain the correct proportion of ingredients in a meal to preserve its integrity. Finally, the following method was applied which keeps each meal intact in terms of ingredients and proportions. The main computational steps for this method are as follows:

a. Calculate the ratio of the total meal cost 2019 (Pre-COVID-19) and 2020 (Post-COVID-19).

b. Apply this ratio to each ingredient.

c. Apply this ratio to each nutrient value of the 2019 cost of meal.

Adjusted ingredient weight $=$ original weight of ingredient $\times(2019$ cost of meal $\div 2020$ cost of meal)

After all the eighteen meals were adjusted, the nutrient composition of all the adjusted meals was calculated in terms of the amount of each nutrient and as percentage of the RDA using the MPT. Total nutrient weekly supply was then calculated for each district based on the six district-specific meals. These values (2020) were compared with the base reference values (2019).

Table 2. Number of food items in food commodity sample by food group/study district

\begin{tabular}{lccccc}
\hline District & Cereals & Legumes/Pulses & Fruits/vegetables & Roots/Tubers & Animal protein \\
\hline Baridya & 4 & 6 & 15 & 3 & 3 \\
Sindhupalchok & 5 & 5 & 8 & 3 & 31 \\
Jumla & 7 & 7 & 11 & 2 & 24 \\
\hline
\end{tabular}


Table 3. Recommended nutrient intake reference values (weekly) for school meals

\begin{tabular}{|c|c|c|c|}
\hline Nutrient & $\begin{array}{l}\text { Recommended } \\
\text { amount/week }\end{array}$ & Measure & Details \\
\hline Energy (kcal) & 11100 & Estimated average requirement $(\mathrm{EAR})^{(15)}$ & $\begin{array}{l}\text { Boys } 7-10=2100 \mathrm{kcal} \\
\text { Girls } 7-10=1800 \mathrm{kcal}\end{array}$ \\
\hline Fat (kcal) & 369.6 & Acceptable macronutrient distribution range $(\mathrm{AMDR})^{(16)}$ & Max $30 \%$ of calories from energy \\
\hline Protein $(g)$ & 177 & Safe level of intake ${ }^{(17)}$ & $\begin{array}{l}\text { Based on India's values, child weight }=25.1 \mathrm{~kg} \text {, } \\
\text { Grams protein per } \mathrm{kg}=1 \cdot 17 \\
\text { Age }=7-9\end{array}$ \\
\hline Zinc (mg) & $67 \cdot 2$ & Recommended daily allowance (RDA) ${ }^{(18)}$ & $\begin{array}{l}\text { Low bioavailability, } 15 \% \\
\text { Age }=7-9 \text { years }\end{array}$ \\
\hline Vitamin-A $(\mu \mathrm{g})$ & 3000 & Safe level of intake & Age $=7-9$ years of age \\
\hline Iron (mg) & $106 \cdot 8$ & Recommended daily allowance (RDA) ${ }^{(18)}$ & $\begin{array}{l}\text { Low bioavailability, } 5 \% \\
\text { Age }=7-10 \text { years }\end{array}$ \\
\hline Calcium (mg) & 4200 & Recommended daily allowance (RDA) ${ }^{(18)}$ & Range $=600-800 \mathrm{mg}$ \\
\hline
\end{tabular}

\section{Typical household food basket}

THFBs were developed specifically for each district and represent notional diets being consumed by the poorest quintile of the population. Typical food baskets have their limitations in that they provide a restricted model of what households actually consume over a week or a month. While the limitations remain, the present paper has attempted to develop credible THFBs based on multiple primary and secondary evidence.

A THFB was designed for a $\mathrm{HH}$ in the first wealth quintile (quintile-1) for each district. Quintile-1 and quintile-2 account for 31 and $22 \%$ of the rural population, respectively (DHS 2016). Our population of interest is quintile- 1 and quintile- 2 as these segments are most vulnerable to the effects of food price inflation on food and nutrition security. In Nepal, quintile- 1 and quintile- 2 spend $64 \cdot 2$ and $62.4 \%$ of the total household budget on food, respectively. We designed THFB for both quintiles, but on further analysis, only quintile-1 THFBs was included. The difference between the two baskets was insubstantial and, therefore, the quintile-2 THFBs were not included in the paper.

Method of Household and THFB construction. The construction of the three THFB involved approximations of household composition, household food consumption and expenditure data. The household of six members for quintile-1 was determined based on national survey findings ${ }^{(19)}$. These assumptions related to age and gender were made and validated from the analysis of primary and secondary data sources ${ }^{(19-22)}$. The household profile was kept the same for all nutrient and cost assessments of the THFBs, by district.
Nutrient reference intakes were used to calculate the daily nutritional recommended amounts for each household member. The average energy requirements were based on age, weight, gender and level of physical activity for each household member. Adult household members were assumed to have moderate physical activity levels (PALs), from 1.70 to 1.90 , except for the older female who had sedentary levels of physical activity at 1.60. The weight of each family member was estimated using data collected from previous research ${ }^{(23)}$. The energy requirements were based on estimated average requirement references sourced from the Joint $\mathrm{FAO} / \mathrm{WHO} /$ UNI expert Consultation in 2001 ${ }^{(15)}$. Safe level of protein intakes was estimated based on guidelines within the WHO/ FAO/UNU Joint Expert Consultation on Protein and Amino Acid Requirements in Human Nutrition ${ }^{(24)}$. The RDA reference values used for zinc, iron, vitamin $\mathrm{C}$ and calcium, and the safe level of intake reference values for vitamin-A were based on the FAO/WHO Guidelines on Vitamin and Mineral Requirements in Human Nutrition ${ }^{(18)}$. Low bioavailability reference values for zinc $(15 \%)$ and iron $(5 \%)$ were used, given that the Nepalese diet contains high levels of antinutrients and low amounts of animal-based foods ${ }^{(18)}$. Fat was limited to contributing up to $30 \%$ of total energy requirements based on the AMDR for the fat of 15$30 \%{ }^{(16)}$. Table 4 summarises the household composition and daily nutritional needs for each household member.

THFBs were designed to reflect likely household consumption of foods over time by converting per capita food consumption (kg) into daily amounts. The THFB were constrained by food expenditure and consumption data for quintile-1. A broad range of foods were selected, including

Table 4. Recommended nutrient intake reference values (daily) for each member of THFB household

\begin{tabular}{|c|c|c|c|c|c|c|c|c|c|}
\hline Household member & Age & PAL & Energy (kcal) & Protein (g) & Fat (kcal) & Vit-A $(\mu \mathrm{g})$ & Iron (mg) & Zinc (mg) & Calcium (mg) \\
\hline Boy & $2-3$ & 1.45 & 1125 & 12 & 337.5 & 400 & $11 \cdot 6$ & $8 \cdot 3$ & 500 \\
\hline Boy & $5-6$ & 1.55 & 1475 & $16 \cdot 2$ & 442.5 & 450 & $12 \cdot 6$ & $9 \cdot 6$ & 600 \\
\hline Girl & $13-14$ & 1.75 & 2375 & 41 & $712 \cdot 5$ & 600 & $65 \cdot 4$ & 14.4 & 1300 \\
\hline Male adult & 37 & 1.9 & 2570 & 46 & 771 & 600 & $27 \cdot 4$ & $17 \cdot 1$ & 1000 \\
\hline Female adult & 28 & 1.9 & 2200 & 37 & 660 & 500 & $58 \cdot 8$ & $9 \cdot 8$ & 1000 \\
\hline Female adult & $45-50$ & 1.6 & 1950 & 35 & 585 & 500 & 58.2 & 9.8 & 1000 \\
\hline Total & & & 11695 & $187 \cdot 2$ & 3508.5 & 3050 & 234 & 69 & 5400 \\
\hline
\end{tabular}

THFB, typical household food basket. 


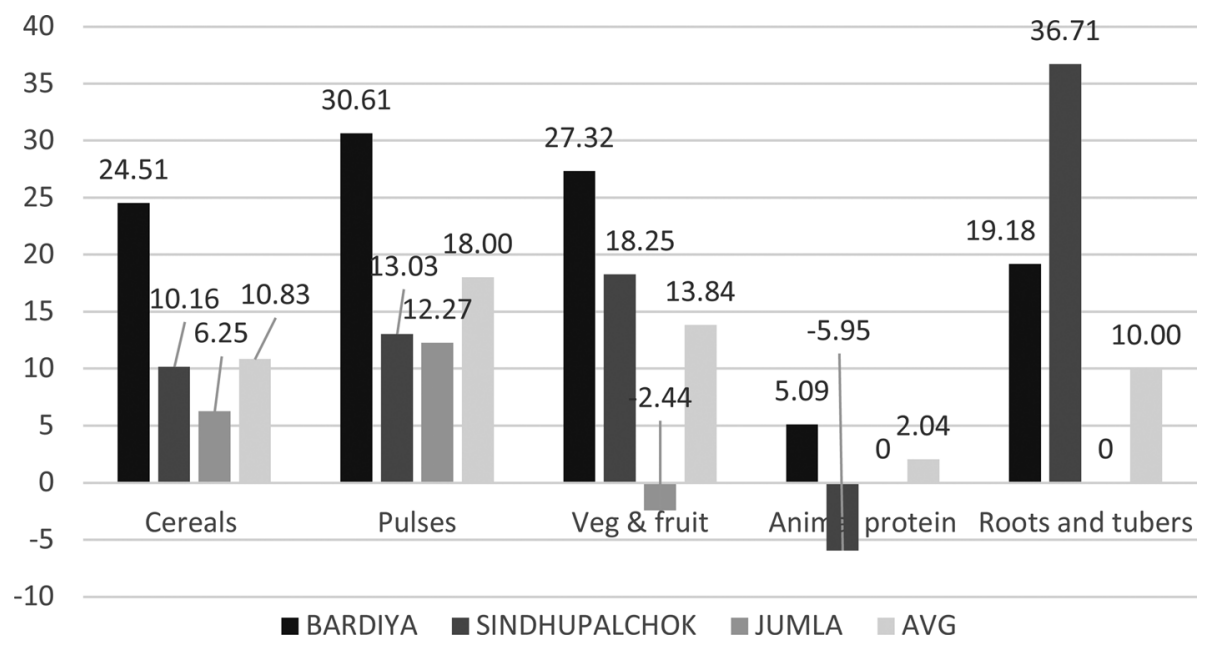

Fig. 1. Percentage increase in food commodity prices between June 2019 (Pre-COVID-19) and May/June 2020 (Post-COVID-19) by food group by study district.

seasonally consumed foods. For example, it is likely that milk is not consumed daily in quintile-1; however, it was included in the basket in small amounts relative to actual consumption over the year. Also, the inclusion of a variety of foods consumed at different times in the year, allowed us to analyse the effect of wider food price changes on the diet.

For each THFB, the total cost of the basket was calculated using food price data for the Pre- and Post-COVID-19 period, i.e. 2019 and 2020 .

Using additional evidence on food consumption behaviours and coping strategies for poor households, we quantified this assumption into proportionate reduction of different food items, to nullify the effect of increased total THFB cost over the reference period. The reduction of weightage was applied uniformly to all districts.

The main computational steps are summarised as follows:

1. The total cost of the THFB using prices from our two reference points were calculated separately and a price difference $(D)$ for each of these was obtained.

2. A weight $(W)$ of food group expenditure reduction was established. This was 2.5 for fruits and dairy, 2 for vegetables, 1 for roots, tubers, pulses, legumes and nuts, $0 \cdot 5$ for cereals and grains, while sugar and oil quantities were not given a ratio, i.e. not reduced.

3. Each weight $(W)$ was applied to the total cost difference $(D)$, to calculate the reduction in expenditure of each food item needed, to maintain the original daily budget for food.

The weight given to each food group was estimated based on evidence of food price sensitivity in the South Asian region and changes in food consumption for the quintile-1 due to food price increases. Food group price sensitivity, from highest to lowest, were dairy, fruits, vegetables, beans/legumes, roots and tubers, then cereals and grains ${ }^{(25,26)}$. In our analysis, no weight was given to oil and sugar, due to the assumption that reductions in calorie rich foods would be avoided where possible.

The cost reduction for each food item was calculated based on a formula, applying the weights mentioned above. The quantity for each food item was then adjusted as per the reduced costing.
Finally, the nutrient composition of the meal based on reduced food quantities was calculated using the MPT and compared with the nutrient composition of the baseline (2019) THFB.

\section{Results}

\section{Food price changes}

Fig. 1 indicates the percentage change in price by the food group for each district.

On average, across the three districts, data show a substantial increase in prices for almost all food groups. Pulses and vegetables and fruits show the highest average price rise at 18 and $14 \%$, respectively, followed by roots and tubers and cereals at around $10 \%$. Animal proteins show a very marginal increase in prices at $2 \%$.

Inter-district price variations by food groups. There is large inter-district variation in terms by food group. For example, in Sindhupalchok, cereal prices increased marginally by $6.2 \%$, while in Bardiya, cereal prices increased by $25 \%$. For fruit and vegetables, prices rose substantially in Bardiya $(27 \%)$ and Sindhupalchok (18\%), on the other hand, Jumla shows a decrease of $2.4 \%$. For roots and tubers, the inter-district price increase range is very wide, from $0 \%$ in Jumla to $37 \%$ in Sindhuplachok.

The food group price changes mask significant intra-food group price variations. For example, in Bardiya, in the cereals food group, price of wheat flour and rice has marginally increased, while the price of dry maize has increased from 52 Nepali Rupee (NPR)/kg to $80 \mathrm{NPR} / \mathrm{kg}$. Similarly, in

Table 5. Meal cost comparison (SMFB)

\begin{tabular}{lccc}
\hline District & 2019 & 2020 & \%Age change \\
\hline Bardiya & 16.34 & 18.05 & 10.47 \\
Sindhupalchok & 13.74 & 14.68 & 6.84 \\
Jumla & 14.50 & 15.44 & 6.48 \\
\hline
\end{tabular}

SMFB, school meal food basket. 
Table 6. Comparative change in nutrient composition (SMFB)

\begin{tabular}{|c|c|c|c|c|c|c|c|c|c|}
\hline \multirow[b]{2}{*}{ Nutrient } & \multicolumn{3}{|c|}{ Sindhupalchok } & \multicolumn{3}{|c|}{ Bardiya } & \multicolumn{3}{|c|}{ Jumla } \\
\hline & $\begin{array}{c}\text { Percentage } \\
\text { change }\end{array}$ & $\begin{array}{l}2019 \\
\text { RDA }\end{array}$ & $\begin{array}{l}2020 \\
\text { RDA }\end{array}$ & $\begin{array}{l}\text { Percentage } \\
\text { change }\end{array}$ & $\begin{array}{l}2019 \\
\text { RDA }\end{array}$ & $\begin{array}{l}2020 \\
\text { RDA }\end{array}$ & $\begin{array}{l}\text { Percentage } \\
\text { change }\end{array}$ & $\begin{array}{l}2019 \\
\text { RDA }\end{array}$ & $\begin{array}{l}2020 \\
\text { RDA }\end{array}$ \\
\hline Calcium (mg) & -8.72 & $25 \cdot 04$ & $22 \cdot 86$ & -14.49 & $24 \cdot 61$ & 21.04 & -9.25 & $24 \cdot 38$ & $22 \cdot 12$ \\
\hline Energy (kcal) & $-6 \cdot 65$ & $20 \cdot 66$ & $19 \cdot 28$ & $-12 \cdot 42$ & $20 \cdot 37$ & $17 \cdot 84$ & -11.82 & $26 \cdot 20$ & $23 \cdot 10$ \\
\hline Fat $(\mathrm{g})$ & -1.50 & 7.98 & 7.86 & $-6 \cdot 15$ & 9.64 & 9.05 & $-2 \cdot 72$ & 10.01 & 9.74 \\
\hline Protein (g) & -6.90 & $52 \cdot 83$ & $49 \cdot 18$ & $15 \cdot 19$ & 52.28 & 44.34 & $-12 \cdot 12$ & $75 \cdot 81$ & $66 \cdot 63$ \\
\hline Vit-A (mcg) & $-5 \cdot 32$ & 4.73 & 4.48 & -11.80 & 26.35 & $23 \cdot 24$ & -10.91 & $29 \cdot 21$ & $26 \cdot 02$ \\
\hline Zinc (mg) & $-6 \cdot 64$ & $25 \cdot 36$ & 23.67 & -9.89 & 23.47 & $21 \cdot 15$ & -11.87 & $28 \cdot 18$ & 24.83 \\
\hline Iron (mg) & -7.47 & $25 \cdot 83$ & 23.91 & -12.58 & 31.87 & $27 \cdot 86$ & -8.08 & 65.90 & 60.57 \\
\hline
\end{tabular}

SMFB, school meal food basket; RDA, recommended daily allowance.

Jumla, the rise in cereal prices is primarily driven by a single commodity, i.e. marsi rice.

\section{School meals}

Cost analysis. As can be seen in Table 5, the unit cost (child/ meal) has shown a similar percentage increase in Sindhupalchok and Jumla of between 6 and $7 \%$, while in Bardiya, the increase is $10.5 \%$.

Diet quality analysis. A summary for the three districts is presented in Table 6. The column '\%age change' refers to the relative change in quantity between the two points in time, i.e. 2019 and 2020. '\%RDA' is used here. '2019 RDA' and '2020 RDA' refer to percentage RDA in a weekly context to suggest the amount of nutrient supplies in a weekly cycle as a percentage of cumulative RDA for six days for each nutrient.

From Table 6, while the percentage change in weekly RDA might not appear substantial in some cases, a small percentage change in RDA can reflect a significant reduction in the actual amount of nutrient supplied. For example, for Sindhupalchok, for vitamin- $\mathrm{A}$, the $\mathrm{RDA}$ has reduced by less than one percentage point from $4.73 \%$ in 2019 to $4.48 \%$ in 2020 , but the decrease in terms of the actual intake of vitamin-A is $5 \%$.

Overall, nutrient intake is negatively impacted across all nutrients in the three districts as can be seen from Fig. 2. On average, protein shows the highest decline at $11.5 \%$, followed by energy at over $10 \%$. All micronutrients show large declines ranging from $9.5 \%$ for zinc to $11 \%$ for vitamin-A.

Fig. 3 illustrates the relative changes for seven nutrients for each of the study districts. The decrease in nutrient levels during the reference period is the largest and substantially above average for Bardiya for all nutrients, except zinc. In Sindhupalchok, the decrease in nutrient levels during the reference period is the least. Jumla is close to the average for almost all nutrients. As can be observed from the figure, the general pattern in a change in nutrient levels, proportionate to each other, is quite similar for all three districts.

We finally calculated the effect of a unit increase in cost, i.e. 1 Nepalese rupee $(1 \mathrm{NPR}=0.008 \mathrm{USD})$ increase on the level of nutrient intake, from our baseline cost of 2019, findings are summarised in Table 7. The impact of 1 NPR cost increase is largest in Jumla, for most nutrients. It is useful to look at the range across districts, as representing the potential impact of a 1 rupee increase on diet quality in Nepal. A 1 NPR increase

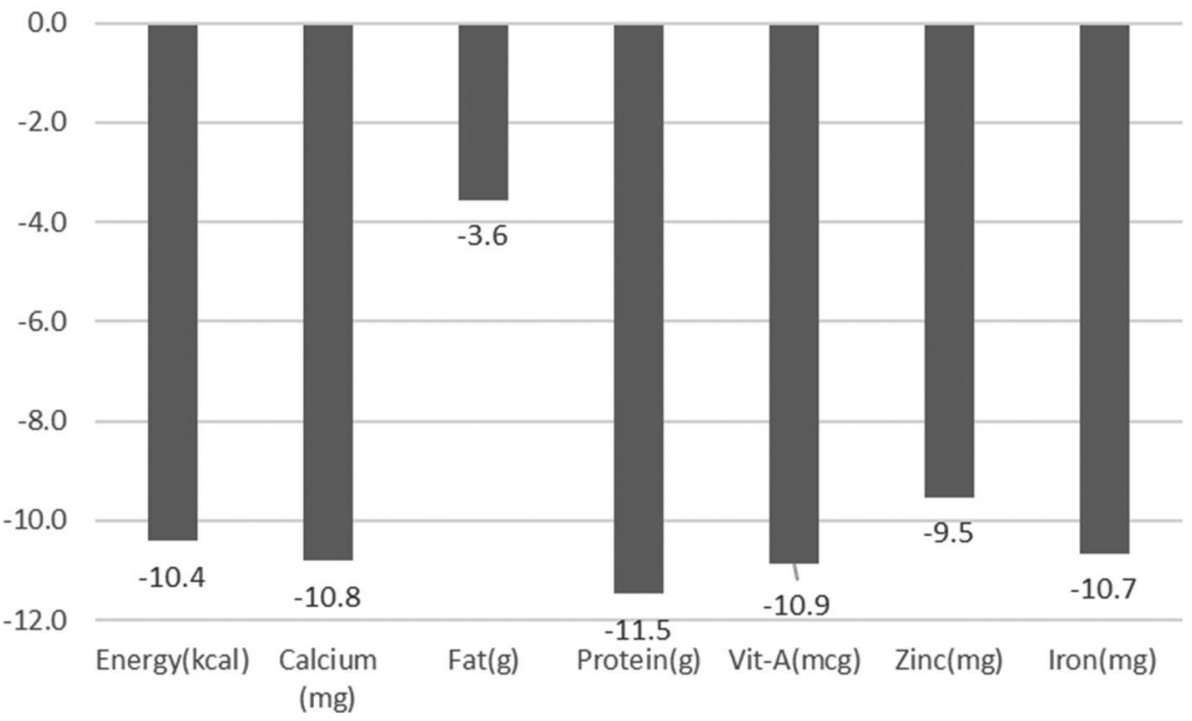

Fig. 2. Average change (\%) in nutrient quantities across study districts for school meal food basket between June 2019 (Pre-COVID-19) and May/June 2020 (Post-COVID-19), due to food price inflation over the reference period. Units used: mg - milligram, mcg - microgram, $\mathrm{g}-\mathrm{gram}$ and kcal - kilocalorie. 


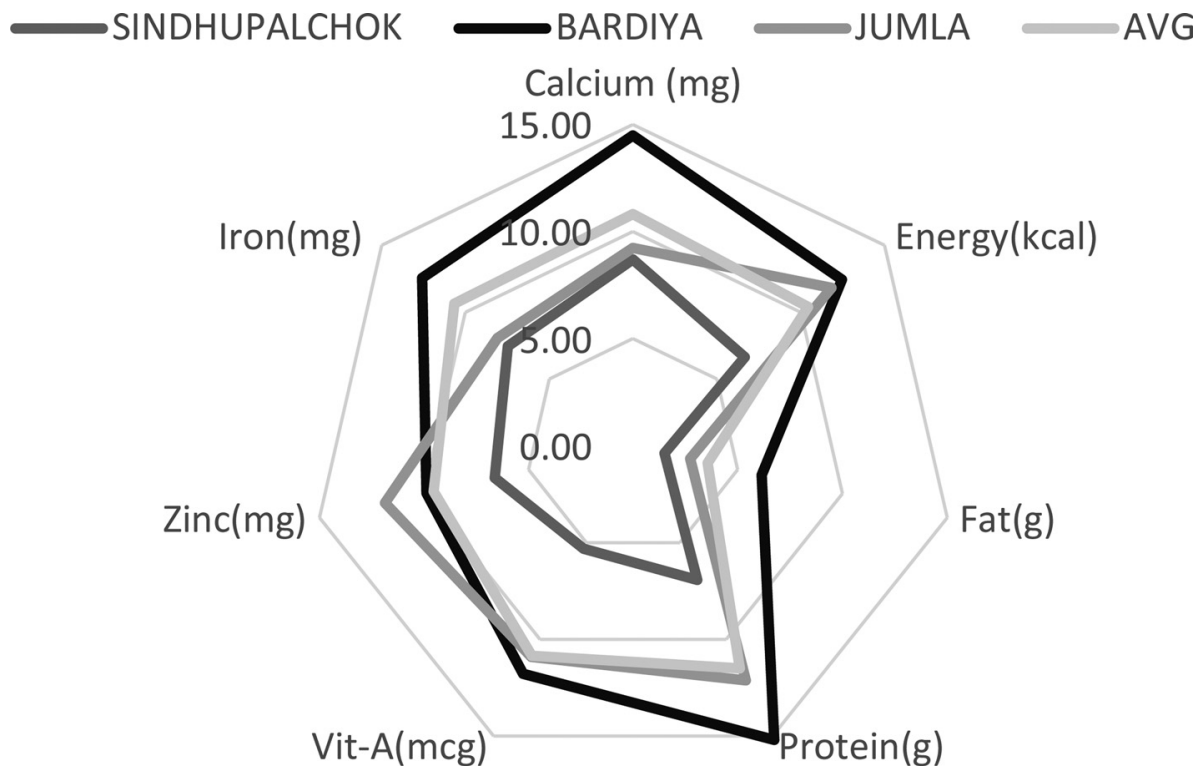

Fig. 3. Percentage decrease in key nutrients by study district and average, for school meals food basket between June 2019 (Pre-COVID-19) and May/June 2020 (Post-COVID-19). Scale (0.00-15.00) represents the magnitude of decrease. Units used: mg - milligram, mcg - microgram, $\mathrm{g}$ - gram and kcal - kilocalorie.

in SMFB cost results in a 5.66-12.63\% decrease in micronutrients and a $7-12.57 \%$ decrease in energy content, across districts.

\section{Typical household food basket}

Cost analysis. Table 8 summarises the total cost of food per day and the percentage increase over the reference period, for a household. The increase in cost varies from $7 \%$ in Jumla to around $11 \%$ in Bardiya and Sindhupalchok.

Diet quality analysis. The results for the three districts are summarised in Table 9. Column '\%age change' refers to the relative change in quantity between the two time points. '2019 RDA' and '2020 RDA' refer to percentage RDA to indicate the amount of nutrient supplied per day as a percentage of cumulative RDA for six days for each nutrient.

While percentage change shows the actual reduction in intake over the reference period, changes in the proportion of the RDA targets that were met by the household for some nutrients are also quite substantial. For example, in Bardiya, for vitamin- $\mathrm{A}$, the intake as a percentage of household RDA has decreased from 86 to $55 \%$. Similarly, in

Table 7. Percentage effect on nutrients for 1 NPR increase in meal cost by district (SMFB)

\begin{tabular}{lccr}
\hline Nutrient & Sindhupalchok & Bardiya & Jumla \\
\hline Calcium (mg) & -9.28 & -8.47 & -9.84 \\
Energy (kcal) & -7.07 & -7.26 & -12.57 \\
Fat $(\mathrm{g})$ & -1.60 & -3.59 & -2.89 \\
Protein (g) & -7.34 & -8.88 & -12.89 \\
Vit-A (mcg) & -5.66 & -6.90 & -11.61 \\
Zinc (mg) & -7.06 & -5.78 & -12.63 \\
Iron (mg) & -7.95 & -7.36 & -8.59 \\
\hline
\end{tabular}

SMFB, school meal food basket.
Jumla, iron shows almost a $10 \%$ decline in the household intake. While looking at the different districts, it is important to note from the figures in '2019 RDA' that there is considerable variation in the baseline diet quality of the THFBs. A comparatively higher percentage decrease for some nutrients over the reference period is simply indicative of the greater impact of food inflation on the particular THFB and not its actual diet quality.

Fig. 4 illustrates the average changes in nutrient levels across districts. In terms of macronutrients, the average reduction is relatively lower for energy and fat, compared to other macronutrients. This is partly a function of weighted reduction methods, used for THFB meal adjustment, which was lower for energy-dense foods. For micronutrients, vitamin-A content reduces by the largest average amount at $37 \%$ followed by iron at $19 \%$. Reduction in zinc is quite low due to the high zinc content in whole grain cereals in all the THFBs.

Fig. 5 illustrates the relative changes for the seven nutrients for each of the study districts. Sindhupalchok and Jumla follow a similar pattern, although the magnitude of reduction in Jumla is substantially greater than the other two districts. Overall, Sindhupalchok shows the least reduction for all nutrients and is below average. Reductions in vitamin- $A$, iron and calcium appear most prominent for all districts.

Finally, we calculated the changes in nutrient intake (\%) when a unit increase in cost, i.e. $10 \mathrm{NPR}$, is applied to the baseline cost of 2019. Findings are summarised in Table 10. We chose 10 NPR as the unit for the THFBs, compared to

Table 8. Cost comparison of THFB by district

\begin{tabular}{lccc}
\hline District & 2019 & 2020 & \%Age change \\
\hline Bardiya & 296.9 & 330.2 & 11.2 \\
Sindhupalchok & 266.0 & 295.0 & 10.9 \\
Jumla & 205.5 & 219.9 & 7
\end{tabular}

THFB, typical household food basket. 
Table 9. Comparative change in nutrient composition (THFB)

\begin{tabular}{|c|c|c|c|c|c|c|c|c|c|}
\hline \multirow[b]{2}{*}{ Nutrient } & \multicolumn{3}{|c|}{ Sindhupalchok } & \multicolumn{3}{|c|}{ Bardiya } & \multicolumn{3}{|c|}{ Jumla } \\
\hline & $\begin{array}{c}2019 \text { RDA } \\
(\%)\end{array}$ & $\begin{array}{c}2020 \text { RDA } \\
(\%)\end{array}$ & $\begin{array}{l}\text { Percentage } \\
\text { change }\end{array}$ & $\begin{array}{c}2019 \text { RDA } \\
(\%)\end{array}$ & $\begin{array}{c}2020 \text { RDA } \\
(\%)\end{array}$ & $\begin{array}{l}\text { Percentage } \\
\text { change }\end{array}$ & $\begin{array}{c}2019 \text { RDA } \\
(\%)\end{array}$ & $\begin{array}{c}2020 \text { RDA } \\
(\%)\end{array}$ & $\begin{array}{l}\text { Percentage } \\
\text { change }\end{array}$ \\
\hline Calcium (mg) & 69 & 58 & -17 & 40 & 28 & -35 & 40 & 32 & -23 \\
\hline Energy (kcal) & 101 & 101 & 0 & 107 & 100 & -8 & 80 & 75 & -9 \\
\hline Fat $(g)$ & 48 & 46 & -4 & 51 & 49 & -7 & 25 & 21 & -13 \\
\hline Protein (g) & 159 & 148 & -7 & 169 & 155 & -10 & 142 & 126 & -16 \\
\hline Vit-A (mcg) & 25 & 18 & -27 & 86 & 55 & -44 & 13 & 7 & -69 \\
\hline Zinc (mg) & 108 & 98 & -9 & 89 & 83 & -8 & 78 & 72 & -11 \\
\hline Iron (mg) & 47 & 41 & -14 & 46 & 38 & -19 & 41 & 32 & -32 \\
\hline
\end{tabular}

THFB, typical household food basket; RDA, recommended daily allowance.

1 NPR for SMFBs to reflect the much larger budget scale of the THFBs. For every 10 NPR increase in the cost of THFB, vitamin-A is reduced by $9-48 \%$, iron by $5-22 \%$ and zinc by 3-8\%. The wide range represents substantial inter-district variation, Sindhupalchok showing substantially lower percentage reduction for all nutrients compared to the other two districts.

\section{Discussion}

The present study shows that food prices have increased substantially over the reference period across all food groups except animal proteins. The findings highlight substantial differences in price changes between the study districts. For example, in Bardiya, prices for fruits and vegetables have increased by $27 \%$, while in Jumla, the prices decreased by $2.4 \%$. The inter-district difference in price inflation can be primarily attributed to the nature of agriculture markets and trade, with nationally and internationally integrated markets being more vulnerable to disruptions in transport. For example, Bardiya district is well integrated in the national agriculture supply chain, due to its location and topography. The closest major agriculture market is in Nepalgunj which is around $2 \mathrm{~h}$ by road. By comparison, Jumla district is located in the high mountain ranges of the Himalayas with an average elevation of $2250 \mathrm{~m}$. The closest major agricultural commodity market is in Surkhet which is around $11 \mathrm{~h}$ travel by road. Agriculture markets in Jumla, especially for perishables like vegetables and fruits are mostly localised, and people depend on their own production for household consumption.

As expected, increased food prices have resulted in a cost increase for SMFB and THFB. For SMFB, the percentage increase in Sindhupalchok and Jumla is between 6 and $7 \%$, while in Bardiya, the increase is $10.5 \%$. For THFB, the increase in cost varies from $7 \%$ (450 NPR/month) in Jumla to around $11 \%(1000 \mathrm{NPR} / \mathrm{month})$ in Bardiya and Sindhupalchok. This increase of 450 and 1000 NPR represents around 6 and $13 \%$ of the monthly household food budget and around 4 and $8 \%$ of the overall $\mathrm{HH}$ consumption, respectively (authors calculation based on DHS 2016).

The estimations based on two different approaches developed in the present paper, i.e. SMFB and THFB, are representative of two very distinct dietary strategies. The SMFBs-based nutrient analysis provides estimates for nutritionally balanced and diverse diets and THFB-based analysis provides estimates for typical diets of poor households. The findings based on both approaches clearly suggest that even a nominal increase in food basket cost can have marked negative implications on the diet quality of the meals, impacting the intake of

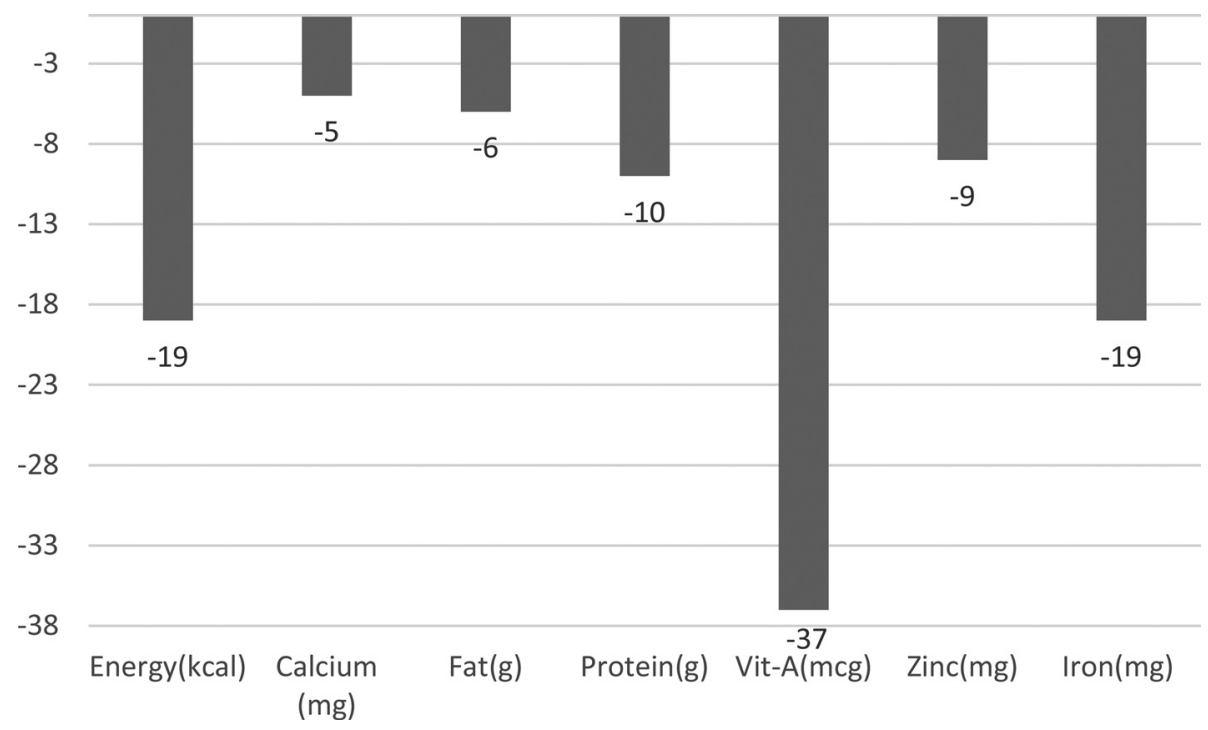

Fig. 4. Average change (\%) in nutrient quantities across study districts for typical household food basket between June 2019 (Pre-COVID-19) and May/June 2020 (Post-COVID-19), due to food price inflation over the reference period. Units used: $\mathrm{mg}-$ milligram, mcg - microgram, $\mathrm{g}-\mathrm{gram}$ and kcal - kilocalorie. 


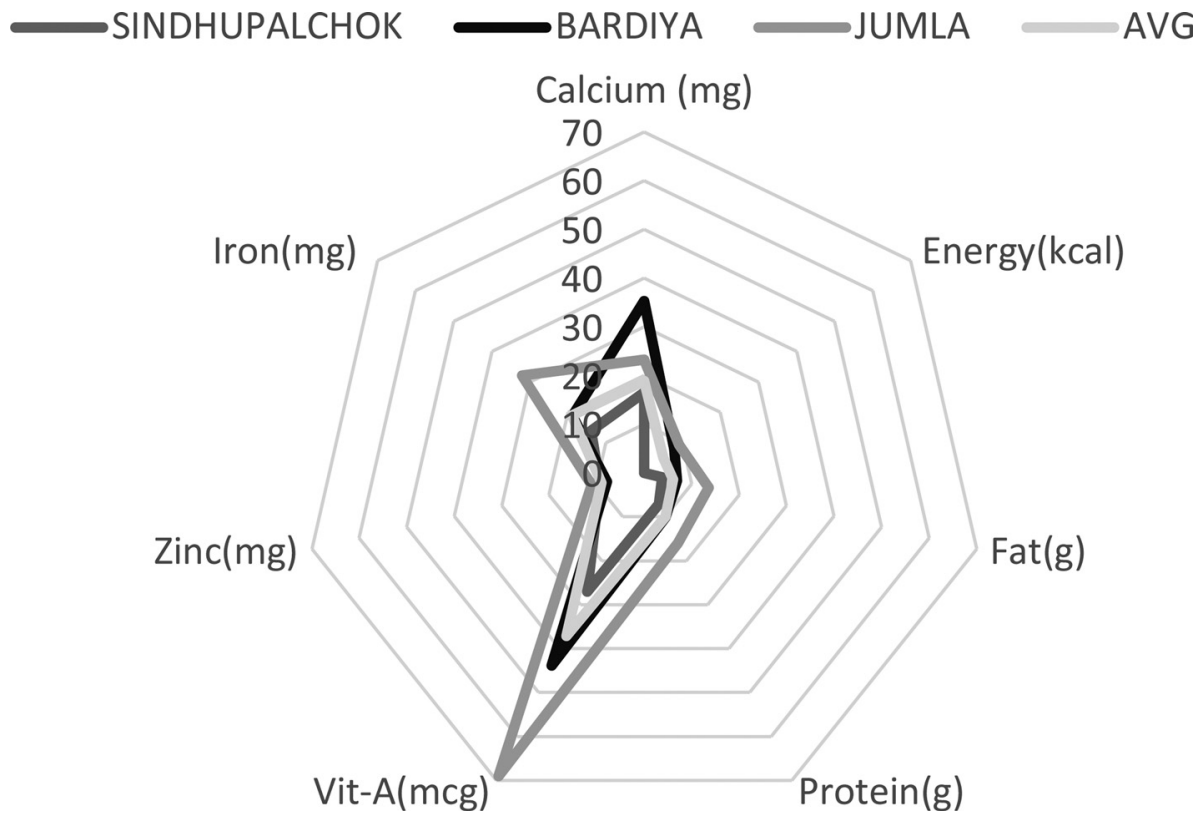

Fig. 5. Percentage decrease in key nutrients by study district and average, for typical household food basket between June 2019 (Pre-COVID-19) and May/June 2020 (Post-COVID-19). Scale (0.00-15.00) represents the magnitude of decrease. Units used: mg - milligram, mcg - microgram, $\mathrm{g}$ - gram and kcal - kilocalorie.

both macro and micronutrients. A 1 NPR increase in the unit cost of SMFB, decreases micronutrient intake by $5 \cdot 66-12 \cdot 63$ $\%$ and energy by $7-13 \%$. A 10 NPR increase in the unit cost of THFB decreases micronutrient intake by $9-69 \%$ and energy by $0-9 \%$. While there are noticeable inter-district variations in the scale of impact, and between SMFB and THFB, the overall conclusion remains consistent.

The significant reduction in the intake of some micronutrients is of particular concern given the severity of the current deficiencies in zinc, iron and vitamin- $A$, as highlighted in the national micronutrient survey ${ }^{(21)}$. Deficiencies in these micronutrients constitute a serious public health crisis and can lead to poor growth, lower school performance, a wide range of diseases, ailments, increased morbidity and mortality ${ }^{(27-29)}$.

The change in consumption patterns to cope with increased prices will have the most serious impact on the diet quality of poor households. In terms of intra-household food allocation, women and children are likely to suffer disproportionately ${ }^{(8)}$. This is especially detrimental during pregnancy, where even small changes in the micronutrient content of diets are associated with significant differences in fetal and infant growth ${ }^{(3)}$.

The analysis of the present paper combined with the evidence from other studies suggests that COVID-19 control

Table 10. Percentage change of nutrients for 10 NPR increase in meal cost by district (THFB)

\begin{tabular}{lcrr}
\hline Nutrient & Sindhupalchok & Bardiya & Jumla \\
\hline Calcium (mg) & -5.72 & -31.54 & -16.14 \\
Energy (kcal) & 0.00 & -7.07 & -6.41 \\
Fat (g) & -1.30 & -6.14 & -9.33 \\
Protein (g) & -2.44 & -9.02 & -11.05 \\
Vit-A (mcg) & -9.34 & -39.10 & -47.79 \\
Zinc (mg) & -3.23 & -6.96 & -7.65 \\
Iron (mg) & -4.83 & -16.82 & -22.18 \\
\hline
\end{tabular}

THFB, typical household food basket. measures are potentially contributing to undermining food and nutrition security, with the poorest being hit the hardest and young children potentially facing lifelong consequences. The evidence emphasises the urgent need to address the impending food security-related public health crisis by implementing mitigating and remedial strategies. As schools continue to remain closed, weekly take-home rations should be explored with clear safety protocols. The school feeding platform can also be leveraged as a public distribution system by providing extra rations during this crisis. National food supply reserve agencies like the Food Management and Trading Company of Nepal can also play a vital role in providing support to food markets and supplies such as ensuring procurement after harvest and enabling aggregation.

The findings of the present study also indicate the importance of resilient localised food systems. This is not to suggest that food supply chains should not be optimally integrated but where possible, local production systems need to be strengthened through deliberate input and output support interventions. Finally, the scale of the current crisis is an emphatic reminder of the need to have an integrated public health-food system approach in response to such a crisis. This can include rapid public procurement of agriculture commodities, distribution of micronutrient supplements and fortified foods, and targeted antenatal care.

The present study looks at the situation two months postimplementation of control measures. As the public health crisis is still unfolding, over the next few months, food prices can be volatile depending on issues of storage, international prices, disruption to summer planting season, etc. It will be useful to conduct multiple small rapid surveys on food production and consumption over the next few months to capture the diverse effects of the pandemic on food and nutrition security on a continuing basis. This can provide useful evidence to inform decisionmaking on contextually relevant food security interventions. 
Some major limitations of the present study need to be highlighted. First, seasonality is an important element in food production and consumption which could not be included in the research design. Second, the research design assumes that purchasing power is constant over our reference period. Due to reduced incomes and wages, the actual impact on diet quality, in all probability is more substantial than indicated by the findings and estimations of the present paper. Notwithstanding the limitations, the present paper provides useful insights on the magnitude and nature of the potential effects of COVID-19 pandemic on food prices and nutrition security. It also highlights the very critical and immediate need for sustained food and nutrition support as a priority, to ensure that the hard-won public health gains of recent years are not entirely lost.

\section{Acknowledgements}

The authors thank Dr Lesley Drake and Prof Gordon Conway, Imperial College London, for reviewing the manuscript and guiding the study. The authors would also like to acknowledge support from colleagues in WFP Nepal and Government of Nepal.

This work was financially supported by USDAs McGovern-Dole Food for Education Program through a WFP Nepal sub-grant to Imperial College London, Grant No. P72642.

S. S. designed the study, undertook final analysis on cost changes and nutrient change modelling and drafted the paper; S. N. constructed the typical household food baskets and modelled nutrient changes for all food baskets; L. A. managed price data collection and computed cost comparisons for school meals; S. T. contributed to the study design and costed typical household food baskets. All authors reviewed the manuscript and provided feedback.

The authors declare that they have no conflicts of interest.

\section{References}

1. Akseer N, Kandru G, Keats EC, et al. (2020) COVID-19 pandemic and mitigation strategies: implications for maternal and child health and nutrition. Am J Clin Nutr 112(2), 251-256.

2. Roberton T, Carter ED, Chou VB, et al. (2020) Early estimates of the indirect effects of the COVID-19 pandemic on maternal and child mortality in low-income and middle-income countries: a modelling study. The Lancet Global Health 8, e901-e908.

3. Block SA, Kiess L, Webb P, et al. (2004) Macro shocks and micro outcomes: child nutrition during Indonesia's crisis. Econ Hum Biol 2, 21-44.

4. Klotz C, Pee S, Thorne-Lyman A, et al. (2008) Nutrition in the perfect storm: why micronutrient malnutrition will be a widespread health consequence of high food prices. Sight Life 2, 6-13.

5. Meerman J \& Aphane J (2012) Impact of High Food Prices on Nutrition. FAO's Expert Consultation on Policy Responses to High and Volatile Food Prices; available at http://www.fao.org/fileadmin/ user_upload/agn/pdf/Meerman_Aphane_ICN2_FINAL.pdf.

6. Ivanic M \& Martin W (2008) Implications of higher global food prices for poverty in low-income countries. Agric Econ 39, 405-416.

7. Arndt C, Hussain M, Salvucci V, et al. (2016) Effects of food price shocks on child malnutrition: the Mozambican experience 2008/ 2009. Econ Hum Biol 22, 1-13.

8. Bhutta ZA, Bawany FA, Feroz A, et al. (2009) Effects of the crises on child nutrition and health in East Asia and the Pacific. Global Soc Pol 9, 119-143.
9. Miller G \& Urdinola BP (2010) Cyclicality, mortality, and the value of time: the case of coffee price fluctuations and child survival in Colombia. J Polit Econ 118, 113-155.

10. Victora C, Adair L, Fall C, et al. (2008) Maternal and child undernutrition: consequences for adult health and human capital. Lancet 371, 340-357.

11. Hoddinott J, Maluccio J, Behrman J, et al. (2008) Effect of a nutrition intervention during early childhood on economic productivity in Guatemalan adults. Lancet 371, 411-416.

12. Ampaabeng S \& Tan C (2013) The long-term cognitive consequences of early childhood malnutrition: the case of famine in Ghana. J Health Econ 32, 1013-1027.

13. Hoddinott J, Behrman JR, Maluccio JA, et al. (2013) Adult consequences of growth failure in early childhood. Am J Clin Nutr 98, $1170-1178$.

14. Gertler P, Heckman J, Pinto R, et al. (2014) Labor market returns to an early childhood stimulation intervention in Jamaica. Science 344, 998-1001.

15. FAO \& WHO (2001) Human Vitamin and Mineral Requirements. Report of a Joint FAO/WHO Expert Consultation, 303 pp.; available at http://www.fao.org/3/a-y2809e.pdf.

16. FAO/WHO (2008) Interim Summary of Conclusions and Dietary Recommendations on Total Fat \& Fatty Acids. Joint FAO/WHO Expert Consultation on Fats and Fatty Acids in Human Nutrition. Geneva, 14 pp.; available at http://www.fao.org/ag/agn/nutrition/docs/Fats and Fatty Acids Summary.pdf.

17. Narasinga Rao BS (2010) Revised Recommended Daily Allowance for Indians 2010. Report of the Expert Group of Indian Council of Medical Research.

18. FAO/WHO (2004) Vitamin and Mineral Requirements in Human Nutrition, 2nd ed., 341 pp.; available at http://apps.who.int/iris/bitstream/10665/42716/1/9241546123.pdf\%0Awww.who.org.

19. Central Bureau of Statistics (2017) Nepal: Annual Housebold Survey 2015/2016. Annual Household Survey, 38 pp.; available at https:// neksap.org.np/allpublications/annual-household-survey-2015-16.

20. Akhter N (2013) Food and nutrition security in the rural plains of Nepal: impact of the global food price crisis. Doctoral Thesis $(\mathrm{PhD})$, UCL, London.

21. Government of Nepal Ministry of Health and Population, UNICEF, USAID, European Union, CDC, N.E. (2016) Nepal National Micronutrient Sumvey, 318 pp.; available at https://www.unicef.org/ nepal/reports/nepal-national-micronutrient-status-survey-report-2016.

22. Ministry of Health, Nepal, New ERA \& ICF (2017) Nepal Demographic and Health Survey 2016. Kathmandu, Nepal, 636 pp.; available at https://www.dhsprogram.com/pubs/pdf/fr336/fr336.pdf.

23. Sudo N, Sekiyama M, Maharjan M, et al. (2006) Gender differences in dietary intake among adults of Hindu communities in lowland Nepal: assessment of portion sizes and food consumption frequencies. Eur J Clin Nutr 60(4), 469-477.

24. FAO/WHO/UNU (2007) Protein and Amino Acid Requirements in Human Nutrition: Report of a Joint FAO/WHO/UNU Expert Consultation. World Health Organization Technical Report Series no. 935, 265 pp.; available at https://apps.who.int/iris/bitstream/handle/10665/43411/WHO_TRS_935_eng.pdf.

25. Green R, Cornelsen L, Dangour AD, et al. (2013) The effect of rising food prices on food consumption: systematic review with meta-regression. BMJ 346, f3703.

26. Muhammad A, D'Souza A, Meade B, et al. (2017) How income and food prices influence global dietary intakes by age and sex: evidence from 164 countries. BMJ Global Health 2, e000184.

27. Allen L, Benoist B de, Dary O, et al.. (2006) Guidelines on Food Fortification with Micronutrients. WHO, FAO UN: 341.

28. Black RE, Allen LH, Bhutta Z, et al. (2008) Maternal and child undernutrition: global and regional exposures and health consequences. Lancet 371, 243-260.

29. Swaminathan S, Edward B \& Kurpad A (2013) Micronutrient deficiency and cognitive and physical performance in Indian children. Eur J Clin Nutr 67, 467-474. 